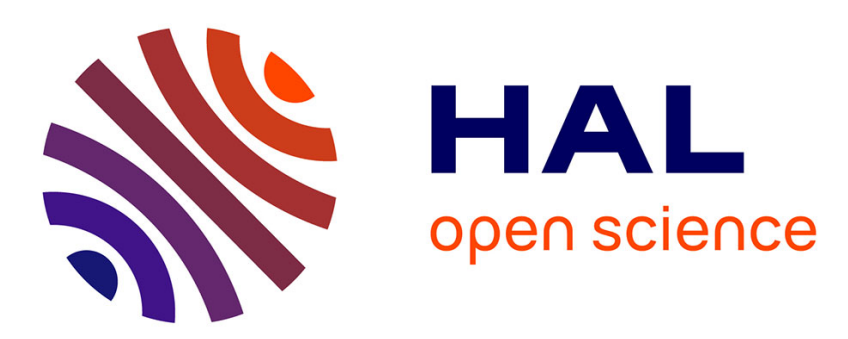

\title{
Ezetimibe blocks hepatitis B virus infection after virus uptake into hepatocytes Authors and affiliations
}

\author{
Julie Lucifora, Knud Esser, Ulrike Protzer
}

\section{To cite this version:}

Julie Lucifora, Knud Esser, Ulrike Protzer. Ezetimibe blocks hepatitis B virus infection after virus uptake into hepatocytes Authors and affiliations. Antiviral Research, 2013, 97 (2), pp.195-197. 10.1016/j.antiviral.2012.12.008 . hal-03315569

\section{HAL Id: hal-03315569 \\ https://hal.science/hal-03315569}

Submitted on 5 Aug 2021

HAL is a multi-disciplinary open access archive for the deposit and dissemination of scientific research documents, whether they are published or not. The documents may come from teaching and research institutions in France or abroad, or from public or private research centers.
L'archive ouverte pluridisciplinaire HAL, est destinée au dépôt et à la diffusion de documents scientifiques de niveau recherche, publiés ou non, émanant des établissements d'enseignement et de recherche français ou étrangers, des laboratoires publics ou privés. 


\section{$\underline{\text { Title }}$}

Ezetimibe blocks hepatitis B virus infection after virus uptake into hepatocytes

\section{Authors and affiliations}

Julie Lucifora*, Knud Esser* and Ulrike Protzer

*both authors contributed equally

Institute of Virology, Technische Universität München / Helmholtz Zentrum München, Trogerstrasse, 30, 81675 Munich, Germany

\section{Corresponding author}

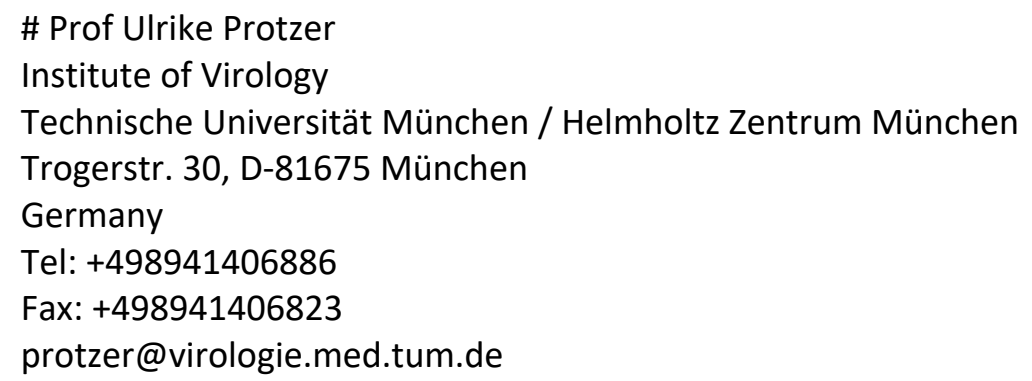




\section{$\underline{\text { Abstract }}$}

Current treatment of chronic Hepatitis B virus (HBV) infection mainly targets viral replication in hepatocytes and leads to curing only in exceptional cases. Despite their potential to improve therapeutic success, no drugs interfering with early infection steps of the hepatotropic pathogen HBV are available to date. Recently, entry of the Hepatitis C virus (HCV) has been shown to occur along hepatic cholesterol uptake pathways and ezetimibe, a drug which blocks this lipid transport, has been shown to inhibit HCV infection. We here investigated the effect of ezetimibe on HBV infection using differentiated HepaRG-cells as a cell-culture infection model. Treatment with ezetimibe inhibited establishment of intrahepatic cccDNA and expression of viral replication markers when cells were infected with HBV virions, while we observed no effect when the HBV viral genome was transduced via an adenoviral vector. Our data suggest that modulating hepatic cholesterol uptake by ezetimibe inhibits early HBV infection and that ezetimibe sensitive lipid transport pathways represent new targets for antiviral therapy in HBV infection.

\section{$\underline{\text { Keywords }}$}

ezetimibe, Hepatitis B Virus, infection, hepatocytes, antiviral 
1 Despite the existence of a prophylactic vaccine, Hepatitis B virus (HBV) remains a major health issue

2 with more than 350 million people chronically infected having higher risks to develop severe liver

3 diseases such as cirrhosis and hepatocellular carcinoma (Lai et al., 2012). Two antiviral strategies

4 against chronic HBV infection are currently approved. Pegylated IFN- $\alpha$ is used as an antiviral as well as to enhance the host's immune defense system. However, it has a poor side-effect profile and only 30 to $40 \%$ of PEG-IFN- $\alpha$-treated patients achieve a sustained antiviral response (Zoulim, 2011). Alternatively, administration of nucleos(t)ide analogs (NUC), which specifically inhibit viral polymerase activity significantly improve the clinical outcomes of the disease. But, NUCs do neither prevent establishment of the so-called circular covalently closed DNA (cccDNA), nor its activity as a transcription template. Since cccDNA, which forms a mini-chromosome, has a long half-life, long-

11 term treatments with NUC are necessary to control HBV, but also lead to the selection of HBV drugresistant strains (Zoulim, 2011). New therapeutic approaches are needed to prevent establishment of

$13 \mathrm{HBV}$, decrease viral drug resistance and improve treatment against HBV. In particular molecules

14 affecting virus entry into hepatocytes are very promising new antiviral strategies because they 15 prevent the initial establishment of HBV cccDNA and can also be used to treat hepatitis delta virus (Lutgehetmann et al., 2012) for which no specific treatment is available yet. Ezetimibe, a FDA-approved selective inhibitor of intestinal cholesterol absorption, is mostly used in combination with statins across various patient populations. Beside its well-documented effect in treating hypercholesterolemia (Lioudaki et al., 2011), ezetimibe was recently proposed to also have antiviral activity since it was shown to block entry of HCV into hepatocytes, an effect caused by inhibition of hepatic cholesterol uptake (Sainz et al., 2012). Since the liver plays an important role in cholesterol homeostasis and hepatocytes are cells specialized for cholesterol uptake (Ikonen, 2008), it seems likely that hepatotropic pathogens highjack this pathway to enter their host cell. As HBV and $\mathrm{HCV}$ target the same host cell and compounds inhibiting entry of both viruses have already been described (Krepstakies et al., 2012), we tested the effect of ezetimibe on HBV infection. 
Differentiated HepaRG cells that support a full HBV replication cycle in vitro (Gripon et al., 2002) were cultured and infected as previously described (Lucifora et al., 2011) and used for this purpose. We first tested the effect of ezetimibe on HBV uptake into hepatocytes. Differentiated HepaRG cells were treated with ezetimibe $2 \mathrm{~h}$ before and during infection with $\mathrm{HBV}$ at $37^{\circ} \mathrm{C}$. $20 \mathrm{~h}$ later, when the HBV inoculum was removed, cells were extensively washed and the amount of intracellular HBV DNA, reflecting the virus that has been taken up, was assessed by qPCR (Protzer et al., 2007;

Quasdorff et al., 2008; Untergasser et al., 2006). This time point was chosen to ensure sufficient time for particle uptake, but before cccDNA establishment is expected (Hantz et al., 2009). Compared to cells incubated with heparin (data not shown) or at $4^{\circ} \mathrm{C}$, we observed only a slight decrease of HBV uptake compared to controls when cells were treated with ezetimibe (Fig. 1A), suggesting a minor effect on binding and uptake of viral particles. To investigate the effect of ezetimibe on subsequent steps of the HBV life cycle, differentiated HepaRG cells were treated again with ezetimibe $2 \mathrm{~h}$ before and during infection with $\mathrm{HBV}$, but the amount of cccDNA and viral antigen expression were analyzed at a late time point (10 days post-infection). cccDNA as well as hepatitis B surface ( $\mathrm{HBsAg}$ ) and e (HBeAg) antigens were strongly (up to 90\%) reduced upon treatment with ezetimibe (Fig. 1B, left panel).

As in HepaRG cells, cccDNA is mostly formed after HBV infection from the incoming virus and not from the recycling toward the nucleus of newly formed nucleocapsids (Hantz et al., 2009), our data suggested that ezetimibe targeted a post-entry step(s) in the HBV life cycle. The inhibitory effect of ezetimibe was shown to be dose dependent (Fig. 1B, right panel) with an effective concentration (EC50) calculated at $18 \mu \mathrm{M}$. The effect was still present even if ezetimibe was preincubated with cells $24 \mathrm{~h}$ and removed before the infection (Fig. 1B, right panel). Taken together, our data indicate that ezetimibe is not directly targeting the HBV particle uptake but rather interferes with a cellular factor important either for viral intracellular transport after initial entry or for a viral-host cell membrane fusion event following endocytosis. To confirm this assumption, we used a recombinant adenovirus transferring and expressing the HBV genome (AdHBV) (Sprinzl et al., 2001; Untergasser et al., 2006) 
but we did observe neither a decrease of HBV gene expression nor of HBV cccDNA establishing in the AdHBV model within the transduced cell (Fig. 1C).

Since transduction of cells with AdHBV only allows the late steps of HBV replication including transcription, replication and secretion of newly formed HBV, we concluded that ezetimibe was not affecting any of these steps but rather earlier post-entry step(s). Finally, no toxicity was observed with ezetimibe neither in infected (data not shown) nor in non-infected cells (Fig. 1D).

In the case of HCV, disruption of NPC1L1 (Niemann-Pick C1 Like 1) function by ezetimibe blocked viral uptake and subsequent hepatocyte infection (Sainz et al., 2012). Interestingly, knock down of neither NPC1L1, nor of Annexin A2 or Caveolin-1 also known to be targeted by ezetimibe (Garcia-Calvo et al., 2005; Smart et al., 2004) had an effect on HBV infection (data not shown) suggesting an alternative antiviral pathway. Since all known targets of ezetimibe share cholesterol-binding properties, we assume that the targeted molecule also binds cholesterol. A direct interaction of ezetimibe with the relatively high amount of cholesterol in the viral envelope (Gavilanes et al., 1982) is unlikely since pretreatment of cells and treatment during infection showed comparable inhibition (Fig. 1B). It is however well possible that the ezetimibe target directly interacts with the viral envelope since HBV infection is dependent on cholesterol in the viral envelope (Bremer et al., 2009).

Taken together, we discovered a potential new therapeutic agent targeting HBV infection at a postentry step, i.e. a step after the initial virion uptake into the host cell but before the establishment of cccDNA as a nuclear persistence from. Our data indicate that ezetimibe rather targets a host factor than the virus itself. This is particularly interesting in the context of therapy-resistant HBV infection, because targeting host cellular factors likely yields more broad spectrum antivirals with minimal or no risk of resistance development. The danger of higher toxicity of such compounds has not been varified for ezetimibe, which it is already in clinical use with minimal if any adverse effects. Of note, ezetimibe might be more potent to inhibit HCV than HBV since we calculated its EC50 in vitro to be 36 times higher than that estimated for HCV (Sainz et al., 2012). In vivo experiments are needed to determine if ezetimibe will be efficient against HBV at 10-20 mg per day, the dose usually 
78 recommended. Finally, as ezetimibe modulates cellular lipid transport, our data also suggest that

79 HBV - as HCV - might hijack lipid transport pathways for establishing itself in the hepatocyte but in an

80 NPC1L1-independent way. This hypothesis is currently under investigation and might lead to a better 81 understanding of early steps of the HBV life cycle. 


\section{Acknowledgment}

We would like to thank Theresa Asen and Romina Bester for their excellent technical support and Steffi Graf for help with AdHBV production.

\section{Figure legend}

Figure 1: Ezetimibe blocks HBV infection after virus uptake into HepaRG cells. Differentiated HepaRG cells were infected by (A, B) HBV or (C) AdHBV. (A,B,C) Treatment with ezetimibe $(100 \mu \mathrm{M}$ unless otherwise indicated) was started $2 \mathrm{~h}$ before the infection and kept during the incubation period of the virus with the cells. In (B), (right panel, before infection) cells were treated $24 \mathrm{~h}$ with ezetimibe $(100 \mu \mathrm{M})$ and washed before infection. (A) 20h post-infection, cells were extensively washed, total DNA was extracted and HBV DNA was detected by qPCR performed using the LightCycler $^{\mathrm{TM}}$ system and analyzed using the second derivative maximum method that includes both normalization to the reference gene (PrnP) and correction for primer efficiency (Roche Diagnostics, Mannheim, Germany). As a positive control for inhibition of uptake, infection was also performed at $4^{\circ} \mathrm{C}$. (B) 10 days post-infection, cells were lyzed, total DNA extracted and HBV cccDNA amounts were analyzed by qPCR. (B, C) Supernatants were collected 10 days post-infection and analyzed for their content in HBeAg and HBsAg by commercial ELISA (Siemens Molecular Diagnostics, Marburg and Abbott Laboratories, Wiesbaden, Germany, respectively). (D) Differentiated HepaRG cells were treated with the indicated concentrations of ezetimibe during $24 \mathrm{~h}$, wash and further cultured. After 10 days, toxicity was assessed by XTT test using the "cell proliferation kit II" (Roche Diagnostics GmbH, Mannheim, Germany). (A,B,C,D) Results are expressed in \% of untreated cells (mock). Data for each group have been analyzed and compared to the mock group using t-test. * means $p<0.05, * *$ means $p<0.01$ and $* * *$ means $p<0.001$. 


\section{References}

Bremer, C.M., Bung, C., Kott, N., Hardt, M., Glebe, D., 2009. Hepatitis B virus infection is dependent on cholesterol in the viral envelope. Cell Microbiol 11, 249-260.

Garcia-Calvo, M., Lisnock, J., Bull, H.G., Hawes, B.E., Burnett, D.A., Braun, M.P., Crona, J.H., Davis, H.R., Jr., Dean, D.C., Detmers, P.A., Graziano, M.P., Hughes, M., Macintyre, D.E., Ogawa, A., O'Neill K, A., Iyer, S.P., Shevell, D.E., Smith, M.M., Tang, Y.S., Makarewicz, A.M., Ujjainwalla, F., Altmann, S.W., Chapman, K.T., Thornberry, N.A., 2005. The target of ezetimibe is Niemann-Pick C1-Like 1 (NPC1L1). Proc Natl Acad Sci U S A 102, 8132-8137.

Gavilanes, F., Gonzalez-Ros, J.M., Peterson, D.L., 1982. Structure of hepatitis B surface antigen. Characterization of the lipid components and their association with the viral proteins. J Biol Chem 257, 7770-7777.

Gripon, P., Rumin, S., Urban, S., Le Seyec, J., Glaise, D., Cannie, I., Guyomard, C., Lucas, J., Trepo, C., Guguen-Guillouzo, C., 2002. Infection of a human hepatoma cell line by hepatitis B virus. Proc Natl Acad Sci U S A 99, 15655-15660.

Hantz, O., Parent, R., Durantel, D., Gripon, P., Guguen-Guillouzo, C., Zoulim, F., 2009. Persistence of the hepatitis B virus covalently closed circular DNA in HepaRG human hepatocyte-like cells. J Gen Virol 90, 127-135.

Ikonen, E., 2008. Cellular cholesterol trafficking and compartmentalization. Nat Rev Mol Cell Biol 9, 125-138.

Krepstakies, M., Lucifora, J., Nagel, C.H., Zeisel, M.B., Holstermann, B., Hohenberg, H., Kowalski, I., Gutsmann, T., Baumert, T.F., Brandenburg, K., Hauber, J., Protzer, U., 2012. A new class of synthetic peptide inhibitors blocks attachment and entry of human pathogenic viruses. J Infect Dis 205, 16541664.

Lai, M.W., Lin, T.Y., Tsao, K.C., Huang, C.G., Hsiao, M.J., Liang, K.H., Yeh, C.T., 2012. Increased seroprevalence of HBV DNA with mutations in the $s$ gene among individuals greater than 18 years old after complete vaccination. Gastroenterology 143, 400-407.

Lioudaki, E., Ganotakis, E.S., Mikhailidis, D.P., 2011. Ezetimibe; more than a low density lipoprotein cholesterol lowering drug? An update after 4 years. Curr Vasc Pharmacol 9, 62-86.

Lucifora, J., Arzberger, S., Durantel, D., Belloni, L., Strubin, M., Levrero, M., Zoulim, F., Hantz, O., Protzer, U., 2011. Hepatitis B virus $X$ protein is essential to initiate and maintain virus replication after infection. J Hepatol 55, 996-1003.

Lutgehetmann, M., Mancke, L.V., Volz, T., Helbig, M., Allweiss, L., Bornscheuer, T., Pollok, J.M., Lohse, A.W., Petersen, J., Urban, S., Dandri, M., 2012. Humanized chimeric uPA mouse model for the study of hepatitis $B$ and $D$ virus interactions and preclinical drug evaluation. Hepatology 55, 685-694. Protzer, U., Seyfried, S., Quasdorff, M., Sass, G., Svorcova, M., Webb, D., Bohne, F., Hosel, M., Schirmacher, P., Tiegs, G., 2007. Antiviral activity and hepatoprotection by heme oxygenase-1 in hepatitis B virus infection. Gastroenterology 133, 1156-1165.

Quasdorff, M., Hosel, M., Odenthal, M., Zedler, U., Bohne, F., Gripon, P., Dienes, H.P., Drebber, U., Stippel, D., Goeser, T., Protzer, U., 2008. A concerted action of HNF4alpha and HNF1alpha links hepatitis $B$ virus replication to hepatocyte differentiation. Cell Microbiol.

Sainz, B., Jr., Barretto, N., Martin, D.N., Hiraga, N., Imamura, M., Hussain, S., Marsh, K.A., Yu, X., Chayama, K., Alrefai, W.A., Uprichard, S.L., 2012. Identification of the Niemann-Pick C1-like 1 cholesterol absorption receptor as a new hepatitis C virus entry factor. Nat Med 18, 281-285. Smart, E.J., De Rose, R.A., Farber, S.A., 2004. Annexin 2-caveolin 1 complex is a target of ezetimibe and regulates intestinal cholesterol transport. Proc Natl Acad Sci U S A 101, 3450-3455.

Sprinzl, M.F., Oberwinkler, H., Schaller, H., Protzer, U., 2001. Transfer of hepatitis B virus genome by adenovirus vectors into cultured cells and mice: crossing the species barrier. J Virol 75, 5108-5118. Untergasser, A., Zedler, U., Langenkamp, A., Hosel, M., Quasdorff, M., Esser, K., Dienes, H.P., Tappertzhofen, B., Kolanus, W., Protzer, U., 2006. Dendritic cells take up viral antigens but do not support the early steps of hepatitis B virus infection. Hepatology 43, 539-547. 
Zoulim, F., 2011. Hepatitis B virus resistance to antiviral drugs: where are we going? Liver Int 31 Suppl 1, 111-116. 
A HBV uptake

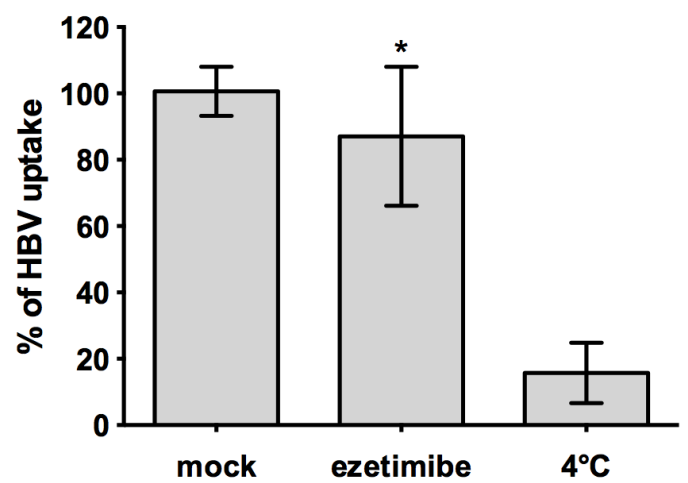

B HBV infection

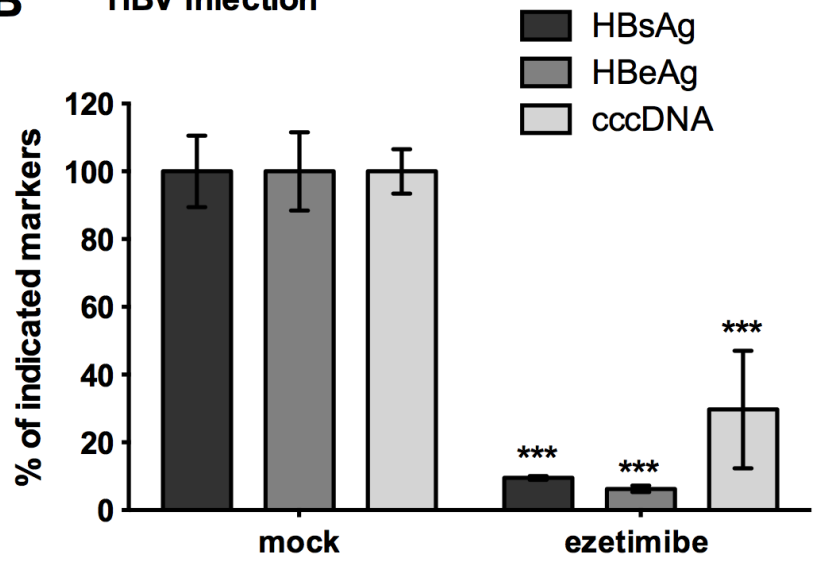

C AdHBV transduction

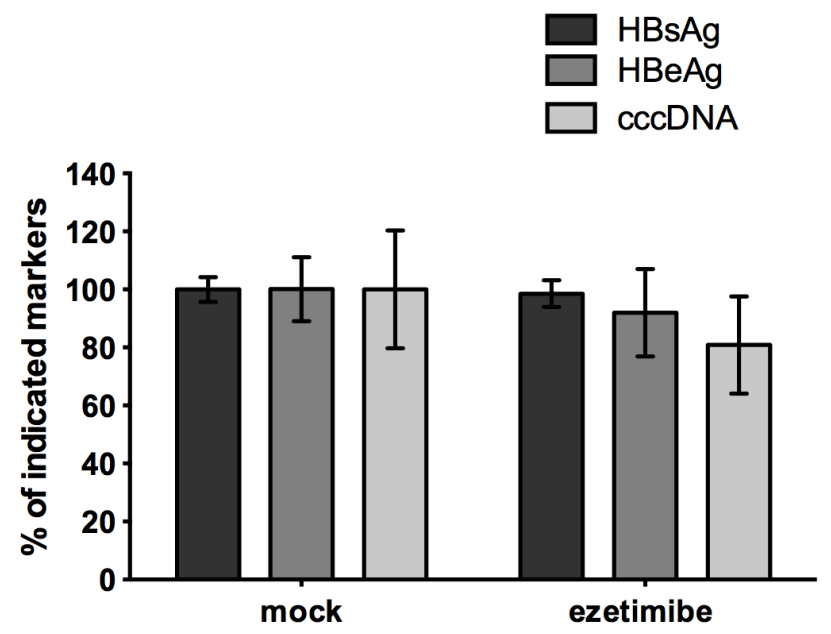

D toxicity
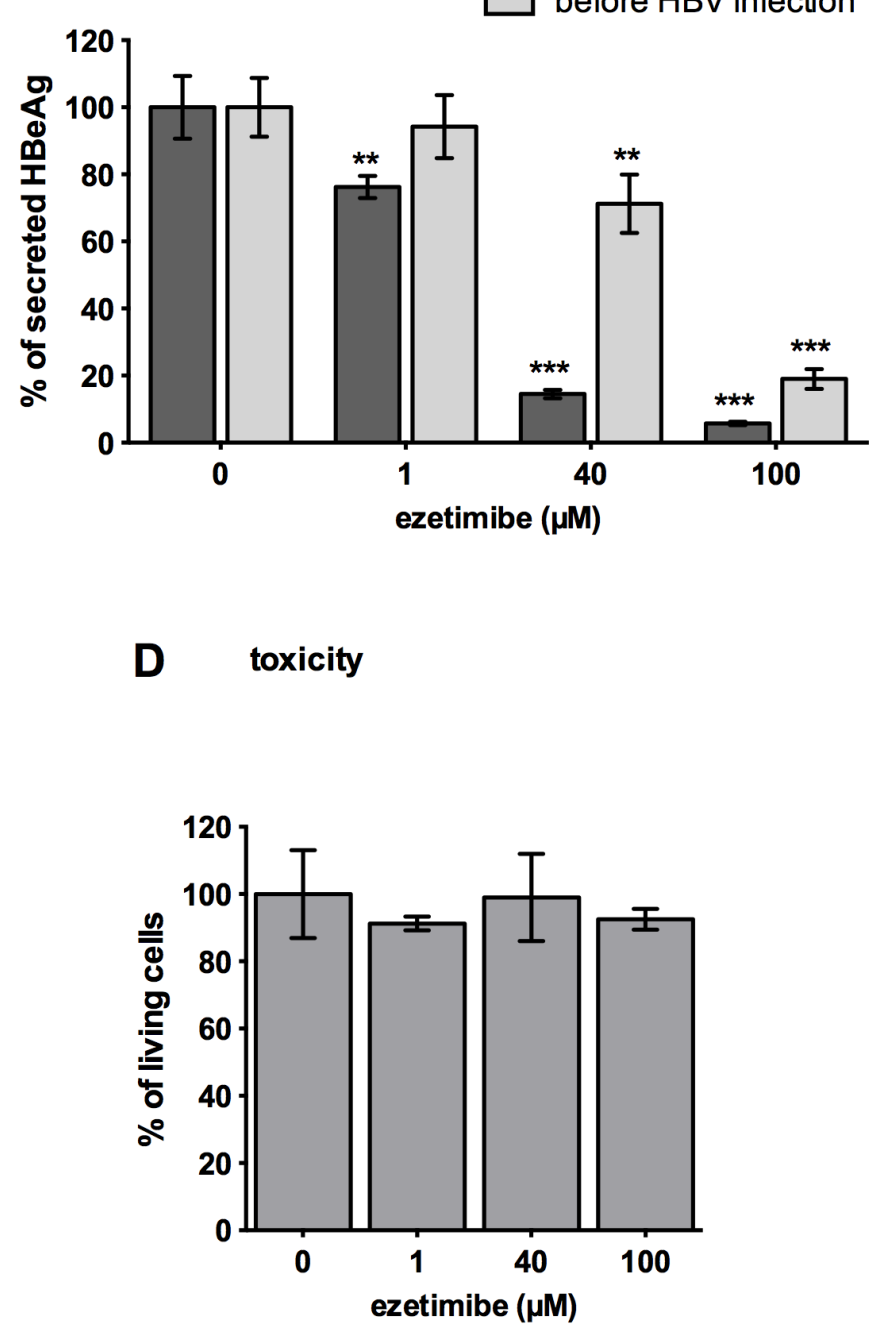